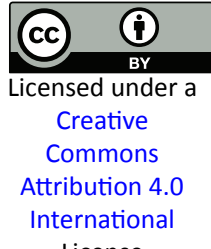

License

\title{
Rule scattering and vowel length in Northern Romance
}

\author{
PAVEL IOSAD \\ University of Edinburgh
}

\begin{abstract}
In this paper I reconsider the synchronic status of distinctive vowel length and vowel lengthening and shortening rules in Northern Romance varieties, in light of Loporcaro's (2015) wide-ranging study of vowel quantity in numerous Romance dialects. Loporcaro (2015) argues that these varieties possess distinctive, phonemic vowel length, and mostly do not have synchronic rules that produce surface long vowels, contrary to many previous analyses of the relevant patterns. In this paper, I argue instead that that lexical vowel length distinctions coexist, in some Northern Romance varieties, with productive phonological rules manipulating vowel quantity. This coexistence is best understood with recourse to the life cycle of phonological processes, and in particular the notion of rule scattering (Bermúdez-Otero 2015). This approach not only allows us to reach an adequate interpretation of the basic facts but also makes further predictions regarding the status of quantity-manipulating rules, which also turn out to be correct, providing further support for the theory of the life cycle.
\end{abstract}

\section{The problem}

In a meticulous and wide-ranging study covering effectively the entire temporal and spatial span of Latin and its Romance descendants, Loporcaro (2015) argues in great detail that the distribution and functioning of phonological vowel length in these varieties is best understood with reference to a sound change of open syllable lengthening in the Late Latin period. Among many other questions, Loporcaro (2015) tackles the synchronic and diachronic status of vowel quantity in northern Italo-Romance dialects.

In these varieties, vowel length appears to function at the phonemic level, allowing for the existence of minimal pairs (as in 1). In addition, we also observe synchronic vowel length alternations (as in 2). The examples are from Friulian. 
(1) Minimal pairs
a. ['va:l]
'(it) costs'
b. ['val]
'valley'

(2) Alternations
a. ['la:t]
'gone-MASC.SG'
b. ['lade]
'gone-FEM.SG'

Alternations such as those in (2) have attracted the interest of phonologists working in the generative tradition because of a range of interesting regularities: a long vowel as in (2a) seems to be predictable in certain contexts. In particular, this long vowel appears when the next syllable contained a historically apocopated short vowel (Late Latin LATU). Alternatively, a connection can be observed between the presence of the long vowel and the laryngeal specification of the following consonant. As a comparison of (2) and (3) shows, we can be justified in postulating a process of final devoicing in (2), deriving (2a) from underlying /lad/. Crucially, a following underlying voiceless obstruent as in (3) does not require the presence of a long vowel.

(3) No alternation before a voiceless obstruent
a. ['mat]
'crazy-MASC.SG'
b. ['mate]
'crazy-FEM.SG'

These apparently systematic restrictions have prompted phonologists to offer a range of analyses in moraic theory treating such long vowels as the products of a synchronic lengthening process, either as an example of compensatory lengthening or deriving the quantitative behaviour of vowels from the prosodic properties of following consonants (e.g. Vanelli 1979, 2005, Hualde 1990, Montreuil 1991, 2010, Repetti 1992, 1994, Prieto i Vives 2000, Iosad 2012, Torres-Tamarit 2015).

Loporcaro (2015) argues that these analyses are wide of the mark because distinctive vowel length has entered the underlying representation of the relevant morphemes. That such distinctive vowel length is required is confirmed by the existence of minimal pairs such as those in (1), where the following consonants are not obstruents. Even firmer evidence for the underlyingly distinctive nature of vowel length in Northern Romance is provided by pairs such as those in (4) and (5), where neither compensation for apocope nor consonant quality could be brought to bear to explain the existence of length; I refer to Loporcaro (2015) for an exhaustive review of the evidence. 
(4) Vowel length contrast in Cremonese proparoxytones
a. ['ta:vula] 'table'
b. ['fabula] 'tale'

(5) Vowel length contrast in Milanese final open syllables
a. [kan'ta:] 'sung'
b. [kan'ta] 'to sing'

Loporcaro (2015) takes the phonemicization of vowel length in cases such as (4) and (5) to be a fatal blow to generative accounts that seek to derive predictable length in other contexts by rule. Instead, he suggests that once vowel length is underlyingly distinctive in some positions, it is underlyingly distinctive everywhere, including where it could be derived by rule. His argument (pp. 132-133) is as follows:

[T]hat Friulian [vowel length] derives from [open syllable lengthening] automatically implies that this is a diachronic change which effected, centuries ago, a restructuring in the underlying form (as no open syllable is there, synchronically, in, say, ['la:t] 'gone').

He thus dismisses attempts to account for alternations such as those in (2) via synchronic phonological computation as similar to the kind of phonological overreach that postulated an underlying /ix/ to account for the lack of trisyllabic shortening in English nightingale.

In this paper I show that there is no contradiction between accepting Loporcaro's (2015) account of the diachronic development of vowel length in Romance and postulating a synchronic rule of lengthening to account for alternations such as those in (2). Key to understanding the tension between phonemicization and productive phonology is the notion of rule scattering (Robinson 1976, Cohn 1998, Bermúdez-Otero 2015), which allows us to understand how a sound change may leave more than one kind of trace in the synchronic phonological system. Specifically, I argue that rule scattering explains why Late Latin open syllable lengthening has produced both underlyingly contrastive vowel length and fed into the creation of a synchronic lengthening rule.

The rest of the paper is organized as follows. In section 2 I briefly recapitulate the analyses of the Northern Romance vowel length pattern proposed in the existing literature. In section 3 I lay out the arguments in support of the proposition that underlyingly distinctive vowel length coexists with a productive stem-level vowel lengthening rule in Friulian. The pattern in Western Lombard is the subject of section 4, where I suggest that the vowel shortening observed in these varieties is simply the 
result of the inversion of a lengthening rule. Section 5 provides a brief conclusion.

\section{The analysis}

In this section I sketch the main ideas of the generative analysis of vowel quantity in Northern Romance dialects. Although, as Loporcaro (2015) shows at great length, distinctive vowel length has historically been characteristic of probably the entire Northern Romance area (that is, the Romance varieties spoken in present-day France and Switzerland, and in Italy roughly north of the La Spezia - Rimini line), the attention of generative phonologists has been largely concentrated on two varieties: Friulian and Western Lombard, the latter normally represented by the dialect of Milan. The basic interpretation of the facts, already sketched in section 2, is as follows. In Friulian, a stressed vowel in a final syllable is lengthened if it is followed by an underlyingly voiced obstruent. The obstruent itself, if it is word-final, is devoiced, and this devoicing counterbleeds vowel lengthening. This is sketched in (6).

(6) Basic analysis of Friulian
a. Underlying representation
b. Vowel lengthening
/lad/ /lade/ /mat/ /mate/
c. Final devoicing
la:d
d. Surface representation
la:t
[la:t] [lade] [mat] [mate]

In Friulian, this generalization is said to be fully regular («del tutto regolare»; Vanelli 2005: 207). This is not, however, the case in other varieties, such as Milanese, where underlyingly voiced obstruents may fail to trigger this vowel lengthening: ${ }^{1}$

(7) Lack of lengthening in Milanese
a. ['mez]
'half-MASC.SG'
b. ['meza]
'half-FEM.SG'
c. ['gøb]
'hunchbacked-MASC.SG'
d. ['gøba]
'hunchbacked-FEM.SG'

\footnotetext{
${ }^{1}$ Unlike Friulian, final devoicing is described for Milanese as only variable (e.g. Sanga 1988).
} 
The synchronic analysis of these facts has largely concentrated on the facts of vowel length before obstruents. As can be gathered from the overviews by Vanelli (2005) and Loporcaro (2015), the principal insight of almost all generative accounts of the facts is that the long vowels in forms such as ['la:t] 'gone' are underlyingly short, and acquire a mora in the course of phonological computation (an exception is Repetti 1992,1994).

The analyses, summarized in table 1, disagree on the source of the second mora. Hualde (1990) and Montreuil (1991) argue that voiced obstruents are moraic in the coda, but devoicing causes them to lose the mora, which is reassigned to the vowel to produce lengthening. In these accounts vowel length in Northern Romance is an instance of synchronic compensatory lengthening, and these analyses are described accordingly in table 1.

Prieto i Vives (2000) and Iosad (2012), on the other hand, see the lengthening as a product of a top-down stress-to-weight requirement operative in oxytones, and suggest that a vowel can acquire the mora only if the following consonant is underlyingly voiced: Prieto i Vives (2000), in line with the accounts just discussed, assumes the availability of this mora is due to the fact the obstruent is voiced, whilst Iosad (2012) argues instead that voiceless obstruents are moraic, and hence block lengthening of the preceding vowel, whilst (de)voiced ones are unable to support a mora and hence their preceding vowel is free to lengthen.

Finally, Torres-Tamarit (2015) treats both voiced and voiceless obstruents as moraic, but offers a serial account in which the prohibition on voiced codas (necessary for final devoicing) prevents voiced obstruents from projecting a mora on their own, and so a foot binarity requirement forces the lengthening of the preceding vowel. However, once devoicing applies, the final obstruent can be incorporated into the moraic structure by being adjoined to the second vocalic mora (symbolized by the dotted line in table 1).

Not all of these analyses, however, address the behaviour of long vowels in contexts other than those preceding an obstruent, or outside a final syllable - as Loporcaro (2015) shows, understanding these is crucial to a full account of the pattern across Northern Romance. Among relevant points of variation it is important to note the following:

- Presence of distinctive vowel length in final open stressed syllables: Milanese [an'da:] 'went' $\neq$ [an'da] 'go.INF';

- Presence of distinctive vowel length before sonorants: Friulian ['mil] 'thousand' $\neq$ ['mill] 'honey'. 


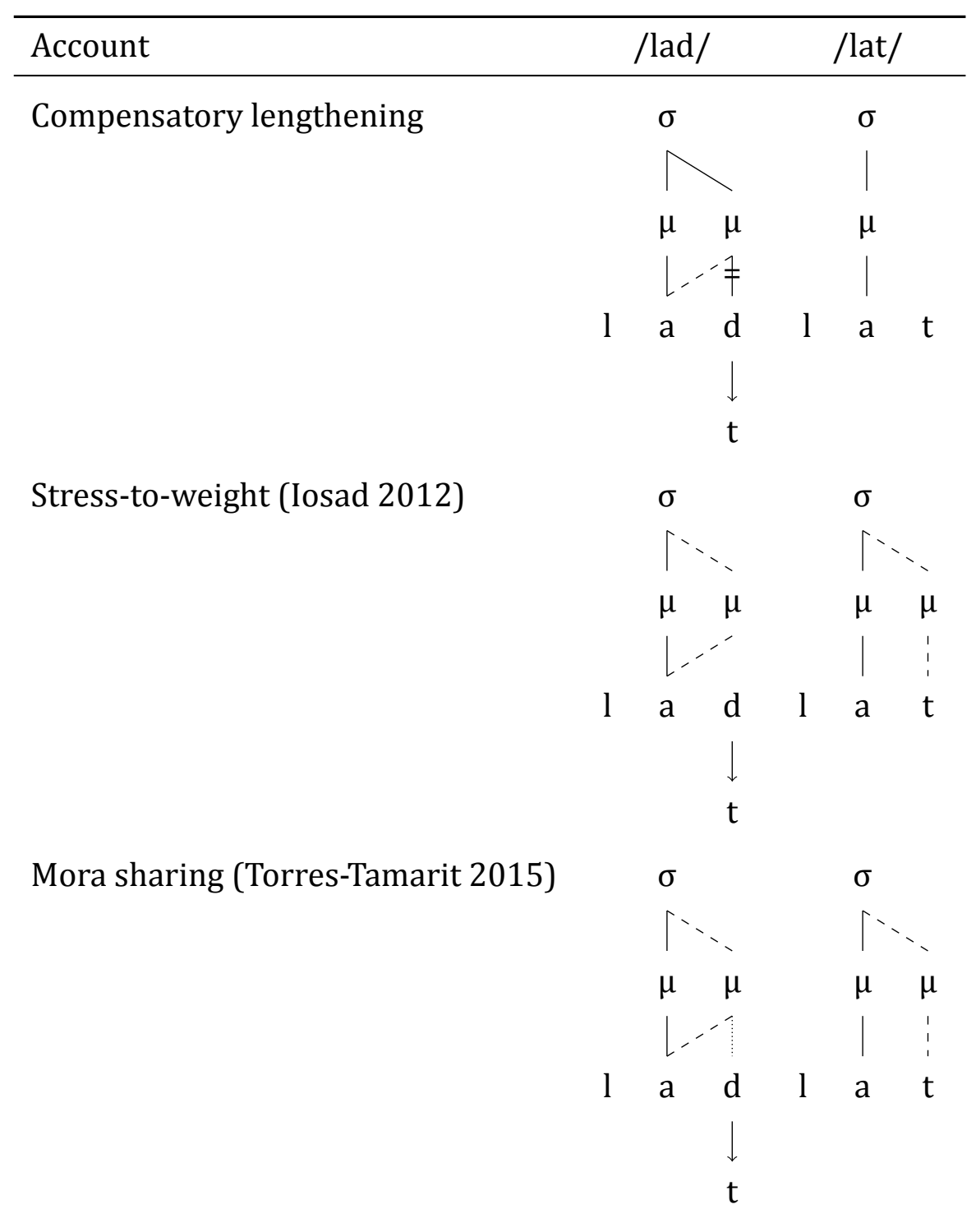

Table 1: Derivations of vowel lengthening 
- Presence of distinctive vowel length in non-final syllables: Cremonese ['ve:der] 'glass' $\neq$ ['veder] 'see.INF', contrast Milanese, where vowels are always short in non-final stressed syllables.

Thus, any account of the relationship between vowel length and the laryngeal specification of obstruents in Northern Romance must by necessity be supplemented by a treatment of vowel length patterning in other contexts. In this connection, Loporcaro (2015) rightly points out that an excessive focus on predictable vowel length loses sight of the fact that at least in some varieties and in some contexts vowel length is unpredictable, and its specification must be included in underlying representations; this is amply demonstrated by minimal pairs such as Cremonese ['ve:der] $\neq$ ['veder], where it is abundantly clear that no contextual information, whether at the underlying or surface level, can explain the patterning of vowel length.

Given the fact that vowel length cannot be derived by rule in at least some contexts in these varieties, Loporcaro (2015) proceeds to argue that even in cases where it could potentially be derived - i. e. preceding wordfinal obstruents - there is no need for an explanation of the presence of vowel length beyond assuming it is present in the underlying representation. That presence, in turn, is explainable with reference to the diachronic source of this length, which Loporcaro $(2007,2011,2015)$ traces to a process of open syllable lengthening in Late Latin (a sound change long ago completed) followed by its loss in varying environments, often including penultimate syllables. Thus, for instance, the development of Friulian [la:t] [lade] 'gone-MASC/FEM.SG' in contrast with ['lat] 'milk' could be summarized as in (8), without prejudice to the exact mechanism and status of the relevant sound changes. ${ }^{2}$
a. Late Latin (with OSL)
LA:.TU LA:.TA LAT.TE
b. Intervocalic lenition
la:du la:da
c. Degemination

late
d. Apocope and vowel reduction
la:d la:de lat
e. Final devoicing
la:t
f. Rhythmic shortening
lade
g. Friulian
[la:t] [lade] [lat]

\footnotetext{
${ }^{2}$ I also do not discuss the consonantal developments in too much detail here, but for expositional purposes this analysis should be sufficient.
} 
In this paper I suggest, however, that there is no necessary incompatibility between the propositions that Late Latin open syllable lengthening resulted in the phonemicization of vowel length in Northern Romance and that alternations such as those in Friulian [la:t] $\sim$ [lade] are produced by a synchronic rule. The key to understanding the relationship between the two phenomena is rule scattering.

\section{Rule scattering and Romance vowel length}

The notion of rule scattering is associated with the theory of the life cycle of phonological processes (see e. g. Robinson 1976, Kiparsky 1995, Cohn 1998, Bermúdez-Otero 2007, 2015, Bermúdez-Otero \& Trousdale 2012, Roberts 2012, Ramsammy 2015). This theory predicts that over time phonological patterns may change their stratal affiliation in the grammar: they start at the postlexical level, then ascend to the word level, then to the stem level, and finally make their mark on the lexicon by shaping the phonological properties of morphemes' underlying representation. Crucially, however, it is not necessarily the case that once a phonological pattern is extended to the next level of this progression, it immediately becomes irrelevant at the level where it resided previously. In fact, we should not expect whatever phonetic or phonological pressures influence a particular sound change to disappear simply because their effects happen to have reached underlying representations. Indeed, it is quite common for cognate patterns to exist at several levels of the grammar simultaneously, even though the details in the different strata may differ.

A classic example of rule scattering is palatalization in English. As shown by Zsiga (2000), English shows two coexisting processes of palatalization: a postlexical, gradient pattern of gestural overlap, whereby a postalveolar fricative may be produced in /s\#j/ sequences (as in miss you), and a lexical, categorical rule of palatalization observable in stemlevel derivation (as in progression from progress). As Bermúdez-Otero \& Trousdale (2012) and Bermúdez-Otero (2015) emphasize, rule scattering is pervasive across languages, and we could well expect to find it in the Romance case as well.

If vowel lengthening in Romance is understood as a scattered rule, then a possible interpretation of the facts is that its effects could be discovered both in underlying representations and in a synchronic phonological pattern. This prediction is borne out by the facts.

It is clear that, as Loporcaro (2015) observes, there are obvious cases where vowel length has entered the underlying representation of morphemes and where, in the absence of other phonological processes, these 
long vowels surface unchanged across the paradigm. Varieties such as Cremonese, which have few positional restrictions on vowel length, allowing it, for instance, freely in paroxytones (['ve:der] 'glass' $\neq$ ['veder] 'to see'), are particularly clear manifestations of this lexicalization.

In other varieties, where the distinction is either completely neutralized outside oxytones (as in Milanese) or relatively rare outside that context (as in Friulian), the relationship between Late Latin open syllable lengthening and modern long vowels is less immediately obvious. Nevertheless, the fact that long vowels can be lexicalized is suggestive, as it is likely that, just as Loporcaro (2015) argues, underlying vowel length distinctions became possible precisely thanks to the effects of open syllables lengthening. A particularly clear case of such lexicalization can be observed with the reflexes of Late Latin $\mathrm{AU}$, which consistently appears in Friulian as [o:]: ${ }^{3}$
a. ['o:k]
'gander' < *AU(I)CU
b. ['o:ce]
'goose' $<$ *AU(I)CA
c. ['po:k]
'few' $<$ *PAUCU
d. ['po:re]
'fear' $<$ *PAU(O)RE

Outside Central Friulian, on which most descriptions of the pattern concentrate, long vowels that do not derive solely from AU can also be found in non-final stressed syllables. For instance, Roseano (2015) gives the following examples from the Friulian of the Lower Valley of the Gorto, a conservative variety belonging to the 'Carnic' group of dialects in the north-west of the Friulian-speaking territory:
a. [ro:za]
'flower'
b. [mu:3a]
'face'

Even keeping to Central Friulian, particularly important for our purposes is the existence of paradigms such as those exemplified by ['o:k] 'gander' $\sim$ ['o:ce] 'goose'. Standard criteria for the analysis of alternations lead us quickly to conclude that the vowel in this lexical item is indeed

\footnotetext{
${ }^{3}$ Another context where long vowels appear in Friulian outside the contested oxytone context is before a historical muta cum liquidā sequence, as in ['parri] 'father', ['vo:li] 'eye' (Heinemann 2007). However, given that synchronic alternations with short vowels and a retained cluster are still possible ([pa'drin] 'godfather', [vo'glon] 'eye-AUG'), the interpretation is less immediately clear.
} 
underlyingly long: it does not alternate with a short vowel, and the presence of vocalic length cannot be ascribed to the properties of the following consonant (which is voiceless). A crucial corollary of this analysis for the wider picture of Friulian phonology is that the grammar of this language does not enforce a shortening of input long vowels even in non-final stressed syllables - fully in line with Loporcaro's (2015) assumption that underlying vowel length distinctions surface faithfully.

A further corollary of this approach is that alternations such as those in (2) become more difficult to analyse with recourse solely to underlying vowel length. If ['la:t] 'gone-MASC.SG' derives from an underlying /la:d/ by final devoicing (this, incidentally, is the analysis by Repetti 1994), then [lade] 'gone-FEM.SG' must derive from /la:de/ — yet we have just established that long vowels in paroxytones are free to surface unchanged in Friulian. This leaves the analyst with two options: either the long vowel in [la:t] is derived by a lengthening rule, as in many of the accounts referred to in section 2, or there is no synchronic phonological relationship between [la:t] 'gone-MASC.SG' and [lade] 'gone-FEM.SG', as proposed by Loporcaro (2015).

The latter option cannot, in the present state of knowledge, be conclusively rejected. There are, however, two arguments that, I suggest, weaken its appeal. First, as discussed particularly by Vanelli (1986), the patterns exemplified by (2) are active in loanword phonology: in borrowings from Italian, vowel length is guided not by vowel length in the source language but by the laryngeal specification of the following consonant in Friulian.

(11) Italian singletons adapted as voiced obstruents, with lengthening
a. [łene'ro:s]
'generous-MASC.SG' < Italian [dzene'ro:zo]
b. [fene'roze]
'generous-FEM.SG'
c. [ban'di:t]
'bandit' < Italian [ban'di:to]
d. [bandi'dut]
'bandit-DIM'

(12) Italian (voiceless) geminates adapted as voiceless obstruents, no lengthening
a. [a'fit]
b. [afi'tut]
'rent' < Italian [a'f:it:o]
'rent-DIM'

Standard Italian itself demonstrates a version of open syllable lengthening, as Loporcaro (2015) discusses at length (see also, for instance, D’Imperio \& Rosenthall 1999, Krämer 2009). Remarkably, however, the principle directly guiding the laryngeal specification of the post-tonic consonant in Friulian (and thus, apparently, the quantitative properties of the 
stressed vowel) is neither the length of the vowel nor the laryngeal specification of the consonant in Italian, but instead the quantity of the consonant. In Standard Italian, a stressed vowel in a paroxytone is lengthened if it is followed by a singleton consonant, as in generoso and bandito. However, this vowel length is not carried over into Friulian as the length of the vowel: as we saw above, underlying long vowels are not expected to shorten in the forms [fene'roze] and [bandi'dut]. On the other hand, the common laryngeal specification of the post-tonic consonants in affitto and bandito does not result in their also having the same laryngeal specification in the Friulian underlying representations /bandid/ and /afit/. The conclusion, then, is that loanword phonology suggests that the relationship between the quantity of the vowel and laryngeal specification of an obstruent is actively manipulated by the synchronic grammar of Friulian, exactly as proposed by numerous previous accounts.

A second consideration is that the required rule in Friulian under this analysis is one of lengthening of underlying short vowels. There are at least two reasons for this. First, as Loporcaro (2015) also emphasizes, a rule of shortening in non-final syllables is empirically untenable for this language, for reasons discussed above with reference to alternations such as ['o:k] $\sim$ ['o:ce]. Second, the V $\sim \mathrm{V}$ : alternation before voiced obstruents is apparently exceptionless in Friulian: there are no examples such as $\mathrm{Mi}$ lanese ['gøb] ['gøba] 'hunchbacked-MASC/FEM.SG.' ${ }^{4}$ With this in mind a rule of lengthening regularly triggered (by whatever mechanism) before (input) voiced obstruents (and some sonorants) is the only way of accounting for the facts. Crucially, this is precisely what is expected under the mechanism of the life cycle of phonological processes. Although the exact conditioning of the rule may change over time, it remains, in its essence, the same requirement for a stressed vowel to be long unless a second mora is provided using other segmental material that drove Late Latin open syllable lengthening; what Repetti (1992) calls the 'bimoraic norm'. In other words, Friulian shows a combination of a lengthening rule and lexicalized vowel length that is exactly the expected outcome of scattering the rule that Loporcaro refers to as 'open syllable lengthening'.

A further prediction of the life cycle is that if the rule has reached the lexicon, it must have been present at the stem level of a stratal phonological grammar before doing so. In other words, if lengthening is a scattered rule in Friulian, then the evidence must be compatible with it

\footnotetext{
4 The exception here is the affricate [d3], which shows a number of complexities; I leave it aside for the moment but return to it briefly below.
} 
being a stem-level rule. This prediction turns out to be correct: there are at least two cases in which vowel lengthening in Friulian interacts in an opaque manner with inflectional morphology.

One case concerns regular (sigmatic) plurals. Although in underived forms vowel lengthening in Friulian is impossible before most consonant clusters, and certainly before clusters of obstruents (['gust] 'taste'), clusters created by the addition of the plural suffix /-s/ do not shorten a vowel that is long in the singular (Finco 2009):
a. ['luxk]
'place'
b. ['lu:ks]
'places'
c. *['luks]

A similar effect is found in verbal inflection, as in the 2SG form of the following paradigm of the verb cedi 'surrender' from Lower Valley of the Gorto Friulian (Roseano 2015):
a. [i 't $\int$ e:t $]$
'I surrender'
b. [tu 't $\mathrm{te}: \mathrm{ts}]$
'you (sg.) surrender'
c. [al 't $f$ e:t]
'(s)he surrenders'
d. [i t fe'din]
'we surrender'
e. [i t $\left.\int e^{\prime} d e j s\right]$
'you (pl.) surrender'
f. [a 't fedin]
'they surrender'

The long vowel in the singular forms is underlyingly short, given the shape of the plural forms; that is, it is lengthened in a final syllable before the underlying /d/. In the 2SG, however, the [s] suffix does not lead to shortening. Both the nominal and the verbal facts are readily accounted for if vowel lengthening takes place at the stem level, and phonotactic restrictions preventing long vowels in underived forms such as ['gust] 'taste' are relaxed at the word level.

A further instance of stratally driven opacity is provided by the affricate [d3]. Unlike other voiced obstruents, it does not trigger the lengthening of a preceding stressed vowel:

(15) No lengthening before /dz/
a. ['mjedze] 'middle-FEM.SG'
b. ['mjet]] 'middle-MASC.SG'
c. *['mje:t $]$

However, long vowels before [d3] are permitted in the 1st and 3rd singular present tense of certain verbs (Yamamoto 1993): 

a. [distru'dzi] 'to destroy'
b. [al dist'ru:tf] '(s)he destroys'

Again, this can be accounted for if the regular lengthening grammar, which does not require lengthening before [d3] (by whatever mechanism), is only active at the stem level. The lengthening in the conjugated form is due to some process (for instance, the introduction of an empty mora) related to inflectional morphology, and thus plausibly active only at the word level, where the restrictions on length are relaxed (for analyses of apparently nonconcatenative vowel lengthening in Friulian verbs, cf. Iosad 2012, Roseano 2015).

Thus, I conclude that at least the Friulian evidence is compatible with an account whereby the Late Latin open syllable lengthening rule is reflected in the grammar as a scattered lengthening pattern: both as a pattern of distinctive underlying vowel length (as proposed by Loporcaro 2015) and an active synchronic rule along the lines offered by analysts in the generative tradition. I have shown here that an understanding of the life cycle of phonological processes allow us to view these phenomena as complementary rather than contradictory. Moreover, the theory of the life cycle when applied to the case of Romance vowel length has been able to make strong predictions - notably regarding the stratal affiliation of vowel lengthening - that, happily, turn out to be correct.

\section{Another afterlife: rule inversion in Western Lombard}

In the previous section I suggested that in some Northern Romance varieties vowel lengthening may still be a scattered rule, applying in (some) stressed syllables. However, I do not intend to claim that the analysis of Friulian should be immediately applicable to all varieties that retain traces of open syllable lengthening. It may well be the case that in other Northern Romance varieties the lengthening rule has reached the end of its life cycle and is only recoverable through its traces in the lexicon. Here, I consider the case of Western Lombard varieties such as those of Milan (Sanga 1988, Prieto i Vives 2000, Loporcaro 2015) and Casale Corte Cerro (Weber Wetzel 2002).

Unlike Friulian, in these varieties vowel length is completely neutralized in all non-final syllables, creating paradigms such as the followings: 
(17) Milanese ${ }^{5}$
a. ['nø:f]
'new-MASC.SG'
b. ['nøva]
'new-FEM.SG'
c. ['gøp]
'hunchbacked-MASC.SG'
d. ['gøba]
'hunchbacked-FEM.SG'

(18) Casale Corte Cerro ${ }^{6}$
a. [dzi'lu:z]
'jealous-MASC.SG'
b. [dzi'lu'ze]
'jealous-FEM.SG'
c. ['gøb]
'hunchbacked-MASC.SG'
d. ['gorbe] 'hunchbacked-FEM.SG'

Thus, in Western Lombard the presence of length in a final syllable cannot be easily derived from the voicing of the final obstruent. These cases are, of course, parallel to the case of lexical contrasts that are possible before certain consonants in Friulian, notably in the case of [l]:
(1, repeated)
a. ['va:l]
'it costs'
b. ['val]
'valley'

Authors such as Iosad (2012), Torres-Tamarit (2015) analyse the Friulian lexical contrasts by assuming some lexical specification of the consonants, in order to arrive at a unified analysis of vowel length before sonorants and obstruents. Iosad (2012) suggests that the difference lies in the moraic specification of the sonorant: underlying / val/ 'it costs' undergoes lengthening because the grammar fails to assign a mora to the coda consonant (like underlying /lad/ 'gone-MASC.SG'), whilst in underlying $/ \mathrm{val}_{\mu} /$ no lengthening is needed. Torres-Tamarit (2015), on the contrary, suggests that the lexical specification is needed in /va $<\mathrm{l}>/$ 'it costs' with an extrametrical [1], because in his approach the grammar will assign a mora to a coda [1], and the extrametricality specification is needed to prevent it.

As Iosad (2012) suggests, this approach could, in principle, be extended to Western Lombard: if lexical items like ['gøb] 'hunchbacked' were

\footnotetext{
${ }^{5}$ For ease of comparison with Friulian, I write the final consonants as voiceless, even though, as noted above, final devoicing in Milanese is variable (cf. Torres-Tamarit 2015). ${ }^{6}$ Note that Weber Wetzel (2002) writes stressed vowels in penultimate syllables with the half-length mark. The important pattern to note is that the two lexical items exemplified here contrast in vowel length when the relevant vowel is in a final syllable but neutralize the contrast in paroxytones.
} 
specified underlyingly with a moraic consonant $\left(/ g ø b_{\mu} /\right)$, and otherwise the grammar was similar to that proposed in section 3 for Friulian, then the existence of lexical contrasts such as those in (17) and (18) would be accounted for.

However, as Loporcaro (2015) points out, better insight can be gained into the Western Lombard system if we start with the diachronic proposal that the extent of lexical vowel length in Northern Romance has shrunk over time: starting with the Late Latin vowel system where open syllable lengthening was found in all stressed syllables, shortening can lead to the disapperance of vowel length contrasts from various prosodic positions, including paroxytones, word-final open syllables, and eventually oxytones as well.

Crucially, because of the prohibition on surface length in non-final syllables, paradigms such as the Friulian ['o:k] ['o:ce] are impossible. Consequently, the simplest synchronic analysis of Western Lombard is one with underlying vowel length and a shortening rule, so that the contrast between ['nø:f] and ['gøp] is underlyingly one between /nø:v/ and /gøb/. No recourse to stored consonant moraicity is necessary, vindicating Loporcaro's (2015) objection to accounts that posit underlying distinctions in consonant moraicity where none seem visible on the surface.

Under this account, forms such as ['nøva] 'new-FEM.SG' are derived by a shortening rule. ${ }^{7}$ This, I suggest, is the result of rule inversion (e.g. Vennemann 1972, Bermúdez-Otero \& Hogg 2003): instead of a lengthening rule targeting a particular position (historically open stressed syllables), the result is a shortening rule that targets the complement of those positions where the effect of the lengthening rule would have been visible. Once again, we observe that the effects of the Late Latin open syllable lengthening are present both in the lexicon, as distinctive vowel length, and as the continued action of a cognate rule, albeit one that has undergone the well-attested process of inversion. Thus, varieties such as Western Lombard provide an interesting example of how the theory of the life cycle can be reconciled with the existence of other changes affecting phonological rules, such as rule generalization (cf. Ramsammy 2015) or, in this case, rule inversion.

\footnotetext{
${ }^{7}$ Note that such a rule is independently needed in the consonant-driven OT accounts of Milanese (Prieto i Vives 2000, Iosad 2012, Torres-Tamarit 2015), because of Richness of the Base. The ranking needs to make sure the phonotactic restriction on long vowels in non-final syllables is respected, so that input long vowels are shortened, and this ranking in fact completely obviates the need for a separate lengthening process.
} 


\section{Conclusion}

Vowel length in Northern Romance has attracted significant amounts of theoretical attention from phonologists working in the generative tradition. An adequate analysis of the phenomenon must, of course, take into account the full range of relevant data, and in that connection Loporcaro's (2015) work provides a rich mine of information that can only be welcomed if further progress is to be made with regard to the theoretical interpretation of the facts. In particular, Loporcaro (2015) points to some very real shortcomings of the available theoretical analyses, which either fail to take cognizance of all relevant data, or are directly incompatible with it.

Nevertheless, it can be argued that Loporcaro's (2015) rejection of any rôle for phonological computation in establishing the observed distribution of vowel length in Northern Romance goes too far in the other direction. He is surely right that in many varieties and for many lexical items the Late Latin sound change of open syllable lengthening has resulted in the establishment of a vowel length distinction in underlying representation that is faithfully reproduced in surface forms. I am also persuaded that his basic diachronic scenario, whereby the prevailing tendency is for the loss of long vowels in various positions over time, is the correct account of the developments. However, this does not mean that there are no varieties where the open syllable lengthening sound change does not also live on as a synchronic pattern, whether a more obviously cognate one such as a bimoraicity requirement for stressed syllables, or transformed into a different pattern, such as one of shortening. This scenario is, in fact, only to be expected under the theory of the life cycle of phonological processes, where it is predicted to arise as a consequence of rule scattering. That this is the right approach to take is, I argue, further suggested by the fact that some specific properties of the relevant rules, such as their stratal affiliation, are also compatible with the theory of the life cycle. I conclude that the theory of the life cycle provides a viable framework for 
an analysis of Northern Romance vowel length that recognizes both its distinctive function and its phonological activity.

\section{Comments invited}

PiHPh relies on post-publication review of the papers that it publishes. If you have any comments on this piece, please add them to its comments site. You are encouraged to consult this site after reading the paper, as there may be comments from other readers there, and replies from the author. This paper's site is here:

http://dx.doi.org/10.2218/pihph.1.2016.1700

\section{Acknowledgements}

For comments on my previous work on Friulian vowel length, thanks are due to Peter Avery, Björn Köhnlein, Marc van Oostendorp, and especially Francesc Torres-Tamarit. The present version of the paper benefited from helpful suggestions and comments by Ben Molineaux, Patrick Honeybone, and Ricardo Bermúdez-Otero. Needless to say, all errors of fact or interpretation are mine alone.

\section{Author's contact details}

Pavel Iosad

Linguistics and English Language

The University of Edinburgh

Dugald Stewart Building

3 Charles Street

Edinburgh EH8 9AD

United Kingdom

pavel.iosad@ed.ac.uk

\section{References}

Bermúdez-Otero, Ricardo. 2007. Diachronic phonology. In Paul de Lacy (ed.), The Cambridge handbook of phonology, 497-518. Cambridge: Cambridge University Press.

Bermúdez-Otero, Ricardo. 2015. Amphichronic explanation and the life cycle of phonological processes. In Patrick Honeybone \& Joseph C. Sal- 
mons (eds.), The Oxford handbook of historical phonology, 374-399. Oxford: Oxford University Press.

Bermúdez-Otero, Ricardo \& Richard M. Hogg. 2003. The actuation problem in Optimality Theory: phonologization, rule inversion and rule loss. In D. Eric Holt (ed.), Optimality Theory and language change (Studies in Natural Language and Linguistic Theory 57), 91-120. Dordrecht: Kluwer.

Bermúdez-Otero, Ricardo \& Graeme Trousdale. 2012. Cycles and continua: On unidirectionality and gradualness in language change. In Terttu Nevalainen \& Elizabeth Closs Traugott (eds.), Handbook on the history of English: Rethinking approaches to the history of English, 691720. Oxford: Oxford University Press.

Cohn, Abigail C. 1998. The phonetics-phonology interface revisited: where's phonetics? In Proceedings of the 1998 Texas Linguistics Society conference (Texas Linguistic Forum 41), 25-40.

D'Imperio, Mariapaola \& Sam Rosenthall. 1999. Phonetics and phonology of main stress in Italian. Phonology 16(1). 1-28.

Finco, Franco. 2009. Fonetiche e fonologije dal furlan centrâl. Gjornâl Furlan des Sciencis 11. 53-85.

Heinemann, Sabine. 2007. Lo sviluppo di muta cum liquida e processi connessi in friulano ed in altri idiomi romanzi. In Federico Vicario (ed.), Ladine loqui: Atti del IV Colloquium Retoromanistisch, 141-180. Udine: Società Filologica Friulana.

Hualde, Jose Ignacio. 1990. Compensatory lengthening in Friulian. Probus 2. 31-46.

Iosad, Pavel. 2012. Final devoicing and vowel lengthening in Friulian: A representational approach. Lingua 122(8). 922-951.

Kiparsky, Paul. 1995. The phonological basis of sound change. In John Goldsmith (ed.), The handbook of phonological theory, 640-670. 0xford: Blackwell.

Krämer, Martin. 2009. The phonology of Italian. Oxford: Oxford University Press.

Loporcaro, Michele. 2007. Facts, theory and dogmas in historical linguistics: vowel quantity from Latin to Romance. In Joseph C. Salmons \& Shannon Dubenion-Smith (eds.), Historical linguistics 2005: selected papers from the 17th International Conference on Historical Linguistics, Madison, Wisconsin (Current Issues in Linguistic Theory 284), 311336. Amsterdam.

Loporcaro, Michele. 2011. Syllable, segment and prosody. In Martin Maiden, John Charles Smith \& Adam Ledgeway (eds.), The Cambridge 
history of the Romance languages. Vol. 1, 50-108. Cambridge: Cambridge University Press.

Loporcaro, Michele. 2015. Vowel length from Latin to Romance. Oxford: Oxford University Press.

Montreuil, Jean-Pierre. 1991. Length in Milanese. In Dieter Wanner \& Douglas A. Kibbee (eds.), New analyses in Romance linguistics: Selected papers from the Linguistic Symposium on Romance Languages XVIII, Urbana-Champaign, April 7-9, 1988 (Current Issues in Linguistic Theory), 37-47. John Benjamins.

Montreuil, Jean-Pierre. 2010. Multiple opacity in Eastern Regional French. In Sonia Colina, Antxon Olarrea \& Ana Maria Carvalho (eds.), Romance linguistics 2009: selected papers fron the 39th Linguistic Symposium on Romance Languages (LSRL), Tucson, Arizona, March 2009, vol. 315 (Current Issues in Linguistic Theory), 153-166. Amsterdam: John Benjamins.

Prieto i Vives, Pilar. 2000. Vowel lengthening in Milanese. In Lori Repetti (ed.), Phonological theory and the dialects of Italy (Current Issues in Linguistic Theory 212), 255-272. Amsterdam: John Benjamins.

Ramsammy, Michael. 2015. The life cycle of phonological processes: Accounting for dialectal microtypologies. Language and Linguistics Compass 9(1). 33-54.

Repetti, Lori. 1992. Vowel length in Northern Italian dialects. Probus 4. 155-182.

Repetti, Lori. 1994. Degenerate syllables in Friulian. Linguistic Inquiry 25(1). 186-193.

Roberts, Philip J. 2012. Latin rhotacism: A case study in the life cycle of phonological processes. Transactions of the Philological Society 110(1). 80-93.

Robinson, Orrin Warner. 1976. A 'scattered' rule in Swiss German. Language 52(1). 148-162.

Roseano, Paolo. 2015. Morfologia non-lineare in romanzo: La flessione verbale del friulano gortano. Archivio glottologico italiano C(1). 85110.

Sanga, Glauco. 1988. La lunghezza vocalica nel milanese e la coscienza fonologica dei parlanti. Romance Philology 41. 290-297.

Torres-Tamarit, Francesc. 2015. Length and voicing in Friulian and Milanese: Or why rule-free derivations are needed. Natural Language \& Linguistic Theory 33(4). 1351-1386.

Vanelli, Laura. 1979. L'allungamento delle vocali in friulano. Ce fastu? 55. 66-76. 
Vanelli, Laura. 1986. La fonologia dei prestiti in friulano. In Raetia antiqua et moderna: W. Theodor Elwert zum 80. Geburtstag, 355-376. Tübingen: Max Niemeyer Verlag.

Vanelli, Laura. 2005. Le vocali lunghe del friulano. In Benincà, Paola \& Laura Vanelli. Linguistica friulana. (Quaderni di dialettologia 10). Padova: Unipress. 159-198. Repr. of Le vocali lunghe del friulano. Quaderni della gramatica friulana di riferimento 1. 69-108.

Vennemann, Theo. 1972. Rule inversion. Lingua 29. 209-242.

Weber Wetzel, Elena. 2002. Il dialetto di Casale Corte Cerro. Contributo alla conoscenza delle parlate del Cusio. Alessandria: Edizioni dell'Orso.

Yamamoto, Shinji. 1993. Alcuni ampliamenti dei casi dell'allungamento vocalico nel friulano. In Laura Vanelli \& Alberto Zamboni (eds.), Per Giovan Battista Pellegrini. Scritti degli allievi padovani, 645-655. Padova: Unipress.

Zsiga, Elizabeth. 2000. Phonetic alignment constraints: Consonant overlap and palatalization in English and Russian. Journal of Phonetics 28(1). 69-102. 